\section{ЧУВСТВА СКВОЗЬ ПРИЗМУ ВМЕСТИЛИЩА}

\section{О. Ф. Задобривская}

Задобривская Оксана Федоровна, старший преподаватель кафедры германских языков и методики их преподавания, Рыбницкий филиал Приднестровского государственного университета им. Т. Г. Шевченко, kesha25@list.ru

Автором предпринята попытка доказать, что чувства категоризуются по образу и подобию вместилища и что они входят в состав криптокласса «Вместилище». Рассматриваются различные типы классификаторов и употребление в них лексических единиц, обозначающих чувства.

Ключевые слова: криптокласс, категоризация, вместилище, контейнер, чувства.

\section{Feelings Through the Lens of the Container}

\section{O. F. Zadobrivskaya}

Oksana F. Zadobrivskaya, https://orcid.org/0000-0003-2016-1197, Rybnitsa branch of Pridnestrovian Shevchenko State University, 12, Gagarina Str., Rybnitsa, 5500, Moldova, kesha25@list.ru

The author attempts to prove that feelings are categorized on the model of the container, that they compose the crypto-class 'Container'. Different types of classifiers are considered, as well as the usage of lexical units denoting feelings within them.

Key words: crypto-class, categorization, container, case, feelings.

DOI: https://doi.org/10.18500/1817-7115-2018-18-4-408-413

При семантическом исследовании основным инструментом является сочетаемость, которая может применяться больше к глаголам, нежели к именам, так как первые называют ситуацию и с помощью закрепленных в их модели управления синтаксических отношений вводят ее обязательных участников ${ }^{1}$. Имя от глагола отличается лабильностью, в которой заключается неспособность этого имени иметь семантическую связь с одной конкретной ситуацией ${ }^{2}$. Так, Е. В. Рахилина полагает, что лексемы с разными значениями, а порой и разные значения одной и той же лексемы могут иметь разную сочетаемость, т. е. «разные сочетаемостные модели» ${ }^{3}$.

Л. Талми говорит, что языки «обычно субкатегоризуют грамматически наряду с семантическими параметрами, в основном это собственное/ общее, исчисляемое/неисчисляемое, односоставное/собирательное, относительное/абсолютное» и т. д. ${ }^{4}$. Базовым семантическим параметром, который помогает сгруппировать существительные, является принадлежность 5 .

Существует скрытая языковая категория, слова которой характеризуются тождеством

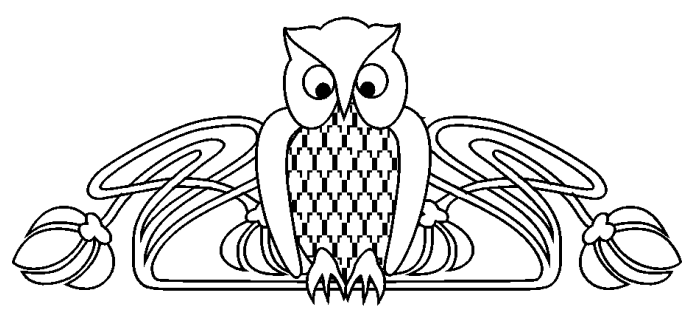

семантического признака. Проявляется данная категория в особенностях лексико-синтаксической сочетаемости. Для описания языковой категоризации лингвисты вводят такое понятие, как «криптокласс». Имена, которые выполняют классифицирующую или категоризующую функцию, называются классификаторами имен ${ }^{6}$.

Система классификаторов - это определенный тип категоризации, они помогают понять явления человеческой категоризации. К. Крейг считает, что система классификаторов в большей степени, нежели лексические таксономии, может помочь в понимании того, как работает процесс категоризации ${ }^{7}$. Лингвистическая классификация помогает категоризовать те явления и действия, в которых принимает участие человек, и эти явления бывают социальными, физическими и функциональными ${ }^{8}$.

К. Алан утверждает, что классификаторы есть во всех языках, и они несут на себе определенные значения. В восточных языках существует больше всего классификаторов по сравнению с другими языками. «Классификатор указывает на воспринимаемые характеристики сущности, которую он классифицирует. Классификаторы - это лингвистические корреляты восприятия, если восприятие данного объекта меняется, то классификатор меняется тоже» ${ }^{9}$.

Классификаторы помогают определить объем криптокласса, т. е. выделить те имена, которые будут входить в состав криптокласса. Когнитивная однородность имен в криптоклассе подчиняется закону аналогии, который позволяет классифицировать «абстрактные явления и сущности по типу и подобию предметов» ${ }^{10}$.

П. Ли отмечает, что главная функция криптокласса - вызвать чрезмерную генерализацию слов, входящих в состав того или иного криптокласса, а не сократить эту чрезмерную генерализацию за его пределами ${ }^{11}$.

В рамках данного исследования мы пытаемся выявить генерализацию слов, идентифицирующих чувства, которые будут входить в состав криптокласса английского языка «Вместилище». Мы рассмотрим, как они категоризуются по образу и подобию контейнера, какими качествами наделяются благодаря этой категоризации.

Мир чувств - это сложная паутина многообразных нитей. Порой осознать, какие испытываются чувства, и понять, какова их многогранность, достаточно сложно. В первую очередь, это связано с психическим состоянием человека. Чувства че- 
ловека помогают выразить его удовлетворенность или неудовлетворенность какими-то действиями, поступками, высказываниями и т. д. Чувства возникают в тот момент, когда человек вовлечен в какую-то деятельность, они влияют на процесс протекания этой деятельности. Спектр чувств зависит от того, какие у индивида потребности, намерения, мотивы, а также от того, какими чертами характера он наделен. Человек может испытывать различные чувства - радость, счастье, грусть и другие, которые являются отражением психической деятельности личности.

Итак, мы отобрали 5 лексических единиц - feeling (1947), happiness (291), pride (219), hope (458) и joy (502) - и проследили, как они категоризуются по аналогии с вместилищем. Всего было проанализировано 3417 словоупотреблений, которые дали возможность выявить признаки вместилища в лексических единицах, обозначающих чувства. Исследование проводилось на базе собрания корпусов Марка Дэвиса ${ }^{12}$, в частности, на базе корпуса NOW (News on the $\mathrm{Web})^{13}$. Сама же языковая категоризация чувств была проведена согласно методике изучения непредметных имен, употребляемых метафорически, т. е. метафоронимов, которая была предложена О. О. Борискиной ${ }^{14}$.

Классифицирующие конструкции, позволившие выявить те единицы, которые могут рассматриваться в рамках данного криптокласса, были подразделены на адъективные, предикативные, субстантивные локативные и глагольные локативные. Адъективные классификаторы - это [а full container] (178), [an empty container] (351) и [a deep container] (1266). Обнаружено, что все чувства могут быть полными или пустыми, а также глубокими.

Результаты количественной обработки данных корпуса показали, что в первую очередь чувства категоризуются по образу и подобию глубокого контейнера: feeling (921), happiness (24), pride (134), hope (29) и јоу (158).

Глубину человеческих чувств можно показать при помощи песен. Одним из самых поющих народов считается индийский, который может заворожить практически любую публику. В Примере 1 говорится об одном из индийских певцов - Утпаленду Чакраборти, в песнях которого можно «углядеть» его эмоции и личные чувства, в глубину которых он погружает.

1) Utpalendu, who used to pour out his emotions and his deep personal feelings through his songs, mesmerized audience all over the world.

Глубоким также может быть чувство патриотизма, которое находит свое проявление при необходимости выказать свои нравственные принципы, направленные в сторону Родины, в случае готовности пожертвовать своими интересами. Патриотизм может проявиться и тогда, когда люди болеют за свою страну на спортивных мероприятиях. В такие моменты кажется, что вся нация, независимо от интересов, объединяется, для того чтобы поддержать свою команду (Пример 2).

$2)<\ldots>$ pressure has been enormous and the whole nation has taken this match into deep patriotic feelings.

Чувство гордости человек испытывает тогда, когда удовлетворен тем, чем он занимается. Положительные моменты, которые приносит его деятельность, провоцируют чувство глубокой радости и удовлетворения. В Примере 3 подчеркивается важность вовлеченности в то дело, которым ты занимаешься. В Примере 4 чувство глубокой гордости переносится на страну, так как, обладая долголетними традициями, несомненно, любой стране будет чем гордиться и будет что продемонстрировать своему народу и будущему поколению.

3) $<\ldots>$ extraordinary young man who was passionate about what he did; who took deep pride in his work; and came into the office every day with enthusiasm, energy $<\ldots>$

4) Mongolia is a country of long traditions and deep pride.

Внутренне чувство удовлетворенности и счастья человек испытывает, в первую очередь, когда его дети здоровы, - несмотря на какие-то неурядицы, которые происходят вокруг, и события, которые не сулят ничего хорошего (Пример 5). Жизнь - это и есть чувство радости, даже если в ней присутствуют эмоциональные перевозбуждения, проблемы, страдания и т. д. Заставляя себя радоваться окружающему миру, человек преодолевает все на своем пути (Пример 6).

5) But Cedar, despite the signs that things are growing worse, feels a deep joy that things will be OK for her child.

$6)<\ldots>$ and the agonies and riddles of life do not exclude deep meaning and deep joy.

Для спортсменов пиком их радостного состояния являются, конечно же, их достижения, завоеванные медали. Усэйн Болт и Майкл Фелпс - два спортсмена, которые на одних только Олимпийских играх выигрывали не один забег или заплыв, а их общее количество наград - глубокая, неподдельная радость, не знающая границ (Пример 7).

7) Usain Bolt and Michael Phelps were mesmerising, the ultimate Olympians transmitting deep, unadulterated joy with their celestial achievements.

Наибольшее количество словоупотреблений в адъективной конструкции [a full container] было опять же зафиксировано со словом feeling - 85 . Наполнять контейнер могут различные явления, но превалирующим оказалось чувство наполненности в том случае, когда речь шла о еде. В Примерах 8-9 можно увидеть негативные последствия после еды в случае переедания, которые могут вызвать неприятные ощущения или даже стать причиной заболевания.

8) $<\ldots>$ can affect levels of a hormone called leptin, which triggers the full feeling after eating, and which can be linked to metabolic conditions such as diabetes. 
9) It can also help prevent gas, bloating and full, heavy feelings in the stomach.

Однако есть примеры, демонстрирующие и положительный эффект от чувства наполненности. Грудное молоко - незаменимая вещь для младенца, содержание белка в молоке обеспечивает хорошее самочувствие ребенка, а также благоприятствует его сну (Пример 10).

10) Some studies suggest the protein content in colostrum provides a full feeling to your baby, enabling him to sleep longer.

Пищевые волокна - это те компоненты пищи, которые выполняют ряд важных и полезных функций в нашем организме. От того, какую пищу мы принимаем, зависит состояние нашей пищеварительной системы и организма в целом, так как правильно подобранный рацион гарантирует чувство наполненности - сытости, а следовательно, хорошее самочувствие и способность выполнять работу (Примеры 11-12).

11) Fiber gives the body a fuller feeling and prevents it from feeling hungry.

12) Natural dietary fiber helps to give a satisfying full feeling, and works on cleansing build-up waste from the digestive system.

Что касается предикативных конструкций, было обнаружено, что чувства могут быть заполнены чем-то - [a container is full] (47) и [a container is filled] (11), а также быть глубокими [a container is deep] (62) и пустыми - [a container is empty] (2). Употребление лексем в последней конструкции говорит об их окказиональном использовании - только две единицы нашли в ней отражение -feeling и hope. В Примере 13 наряду с другими чувствами, такими как обоняние и вкус, демонстрируется потеря характеристик опустошенности, душевной пустоты, которая заставляет волноваться, страдать, испытывать дискомфорт, потерю веры. В Примере 14 говорится о том, что необходимо брать в свои руки инициативу и не надеяться только на счастливую случайность, взращивая в себе ничем не подкрепленную надежду.

13) Scent is empty. Taste is empty. Even feelings are also empty.

14) $<\ldots>$ and make the needed changes necessary to take control of our destiny, hope is empty.

Заполнить же чем-то можно собственно сами чувства (1) и радость (2), хотя это и окказиональные употребления, счастье (3) и надежду (5). Так, например, художественный фильм сравнивается с радостью, которая заполняется удивительными деталями и особенностями, которые зритель все больше обнаруживает при очередном просмотре (Пример 15).

15) The movie itself is always a joy, filled with delightful detail and oddities that seem to reveal more with each viewing.

В Примере 16 следует отметить наличие оксюморона - счастье заполняется печалью, которую испытывает автор от того, что ему не с кем разделить это прекрасное чувство, свидетельствующее о полноте и осмысленности жизни.

16) My happiness is filled with sadness without you to share it with.

Субстантивные локативные классификаторы в большинстве своем показывают, что в контейнер можно что-то вложить, в него можно погрузиться, или же что-то находит свое место в нем. Единичный случай показал, что из чувств можно что-то изъять - [withdrawal from a container] (2). В Примере 17 чувства печали - источник психического расстройства, депрессии, продуцирующей бессмысленное и ничем неоправданное чувство вины.

17) But symptoms of depression can come as withdrawal from people, feelings of sadness, unnecessary guilt.

Субстантивные локативные классификаторы не помогли зарегистрировать большое количество словоупотреблений. Однако те, которые были обнаружены, показали, что, например, можно погрузиться в счастье - [a dip in a container] (12) и в сами чувства - [immersion in a container] (1). В Примерах 18-19 погружение связано с научными исследованиями, затрагивающими сферу Средневековья, средневековой жизни. В Примере 20 полное погружение в чувства объясняется тем, что найдено хорошее место для ночлега, создающее благоприятную атмосферу.

18) The study found a substantial dip in happiness during the middle of people's lives.

19) New study by researchers at the University of Melbourne has confirmed a dip in human happiness during middle age.

20) $<\ldots>$ unusual location fully self-sufficient for a complete night out. It's full immersion in feeling.

Погружение в чувства может быть также выражено при помощи другого классификатора - [a drop in a container] (32): happiness (28), feeling (4). Окунуться можно в супружеское счастье, чтобы обеспечить благополучие для себя и своей второй половинки (Пример 21), или же испытывая тревогу по поводу будущего, наполненного мрачностью и тревогой, и имея негативный взгляд на какие-то проблемы, можно погрузиться в чувство пессимизма (Пример 22).

21) Couples can often experience a drop in marital happiness that affects one's overall well being.

22) $<\ldots>$ of Wolverhampton conduced a study a while back that concluded a significant drop in feelings of pessimism about the future and increases in hedonic tone.

Анализ словоупотреблений в глагольных локативных конструкциях показал, что наиболее часто лексические единицы, обозначающие чувства и категоризующиеся по образу и подобию контейнера, употребляются в конструкциях [live in a container] (312) и [be/exist in a container] (243). По единицам статистика выглядит следующим образом: [live in a container] - feeling (13), happiness (74), pride (1), hope (190) и јоy (34); [be/ 
exist in a container]-feeling (127), happiness (26), pride (6), hope (32) и јоy (52).

Жить в мире и согласии значит находиться в гармонии с самим собой, доставлять радость другим людям, делать близких людей счастливыми. Каждый человек имеет право на свое собственное счастье (Пример 23). В Примере 24 можно увидеть некий отрицательный смысл фразы “жить в надежде', о чем свидетельствует следующее после него предложение, в котором говорится, что надежда - это не панацея от всех болезней. Надежда не должна покидать человека никогда, но, находясь в бездействии, надеяться на чудо нет смысла.

$23)<\ldots>$ the right to live in peace and happiness with their loved ones, the right to education and selfaccomplishment $<\ldots>$

24) People who hope for miracles live in hope. Hope is no panacea for all our ills nor a substitute for hard work over those.

'Быть в чувствах' может иметь значение 'иметь мнение', как в Примере 25. В данном случае человек желает высказать свою точку зрения на проблему, так как считает чужой взгляд субъективным. В Примере 26 подчеркивается благополучие регионов, о которых говорит автор. В них люди не просто существуют, а живут в гармонии и радости.

25) Look, this isn't an objective assessment. I'm in my feelings, too, if you can't already tell.

26) Goa has assimilated the essence of both regions where people coexist in harmony and joy.

В интралокативной экзистенциальной конструкции [there is smth in a container] по образу и подобию контейнера могут категоризоваться все исследуемые единицы-чувства - feeling (26), happiness (7), pride (2), hope (1) и јoy (4). Так, в чувствах могут содержаться различные абстрактные явления: в избыточных чувствах - опасность (Пример 27); в гордости народа Китая - ирония, которая связана с тем, что Китай славится производством изделий, продаваемых по низкой цене, но обладающих низким качеством (Пример 28); в радости - нечто отрицательное - подрыв веры и надежды (Пример 29).

27) There is danger in the exuberant feeling of ever-growing power which the advance of the physical sciences has engendered.

28) There are ironies galore in China's pride in surpassing the U.S. in auto production.

29) Keyes understands something essential: there's subversion in joy.

Или же можем наблюдать отсутствие какихлибо явлений в контейнере: в счастье- отсутствие морального рывка, способствующего внутреннему удовлетворению жителей Великобритании и США (Пример 30); в надежде - отсутствие стыда за стремление поучиться некоторым вещам даже у соперника (Пример 31).

30) Yet over the same period there has been no increase in happiness (in Britain or the US), as measured by surveys.
31) May they learn from their eternal rival; there is no shame in that hope.

Если мы говорим о направлении погружения, то стоит отметить глагольные локативные конструкции с предлогом into. Однако количество словоупотреблений в них не так велико. Выделим те из них, в которых нашли отражение более двух единиц-чувств. Это [delve into a container] (24) и [put into a container] (11). В первой из них употребляются feeling (14), happiness (1), hope (4) и joy (5), а во второй happiness (3), pride (1), hope (10).

Можно погрузиться в чувства, для того чтобы разобраться в своих ощущениях и понять, что необходимо в данный момент. Считается, что «копаться» в чувствах - прерогатива женщин, мужчины редко дают волю чувствам, отсюда и возникает проблема (Пример 32). Погружение происходит не только в свои чувства, но и в чувства других людей, с целью выяснения деталей жизни отдельного человека, например, в его радости и горести (Пример 33).

32) The problem is that men don't take time between rounds to delve into their feelings.

33) $<\ldots>$ but I'm incredibly grateful I had the opportunity to delve into the joy and terror that makes up a year in Cory's life.

Примеры 34-35 показывают, что погружение - это цель углубленного изучения какого-то явления. Счастье - это внутреннее состояние человека, коэффициент которого, согласно научной точке зрения, может быть измерен (Пример 34). На рынке труда проводятся исследования в области возникновения новых классов, а также их потребностей, возможностей, желаний и надежд. Задача такого рода исследований - выяснить, чем они планируют заниматься и какова их цель пребывания на этом рынке (Пример 35).

34) Not only are researchers delving into the happiness of individuals, the happiness quotient of entire nations is being measured.

35) Various research firms have delved deeper into the hope and desires of these new emerging consumer classes.

Вкладывая что-то в свои чувства, человек надеется получить из этого выгоду для себя, для своего благополучия. Счастье зависит от того, какие люди находятся рядом, поэтому энергия и силы, которые вкладываются во времяпрепровождение с семьей, принесут то самое благосостояние, о котором каждый мечтает (Пример 36). Пример 37 - это единственный пример с локативной конструкцией [into a container] в рамках исследования лексической единицы pride на предмет категоризации по образу и подобию контейнера. В данном случае гордость ассоциируется с предметом - машиной, в которую Льюк вкладывает все свое время и все свои средства.

36) We can put more energy into wellbeing, happiness and spending time with family and friends. 
37) $<\ldots>$ his car, the scrupulous hours of dedication and investment that Luke put into his pride and joy, showed what a conscientious and meticulous person he was.

В надежды можно вложить и нечто отрицательное - вред, который ставит под сомнение способность избежать поражения, мешает достичь хорошего результата в начатом деле (Пример 38).

38) This will put a dent in Sunderland's hopes of avoiding a defeat today!

Нахождение внутри вместилища подтверждается локативной конструкцией [inside a container] (18). Она свидетельствует о том, что все слова категоризуются по аналогии с вместилищем, так как что-то находится в полости объекта - чувства, является его содержимым. В чувствах можно затеряться, прежде погрузившись в них (Пример 39); в счастье - обнаружить то, что так долго искали для своего благополучия (Пример 40); в надежде - жить, представляя себе, что эта надежда - укрытие от бед и невзгод (Пример 41). Можно находиться в радостях и горестях, будто в ловушке внутренних чувств (Пример 42).

39) Instead of that mundane, we are taken inside the emotional feeling of being lost, cut off from home $<\ldots>$

40) Maybe we will discover inside the happiness that has eluded us for so long while we've been searching in all $<\ldots>$

41) The most you can do is live inside that hope, running down its hallways, touching the walls on both sides.

42) From being trapped within myself, inside the joys and sorrows that make up Peter Fin and which reside like tiny, floating $<\ldots>$

Из контейнера-чувства можно что-то достать [take from a container] (52)/[take out of a container] (10)/[get out of a container] (17), что-то извлечь [draw/be drawn from a container] (21), [remove from a container] (14), или что-то может брать начало из этого вместилища [stem from a container] (113).

Радость - это и есть счастье, внутреннее чувство удовлетворения, причем для каждого радость - своя. В Примере 43 герой вдохновляется, получает радость от простой игры в футбол, он как бы достает счастье из этой радости.

43) $<\ldots>$ and of the amount of happiness he took from the simple joy of playing football.

Из дореволюционной императорской гордости автор извлекает свои истории (Пример 44), а из чувств, возникших после просмотра фильма, можно вытянуть человека, погрузившегося в себя, в свои мысли, впечатления, воображение (Пример 45).

44) Drawing from pre-revolutionary imperial pride, and historic Orthodox culture, his patriotic narrative was invoked to justify $<\ldots>$

45) Sometimes they even remove you from the feeling of the movie you just watched.
В Примере 46 счастье выступает вместилищем для противоположного чувства - гнева, который берет свое начало в счастье, продуцируется благополучием другого человека.

46) I think my anger towards you stems from your happiness with your own being.

Таким образом, было получено подтверждение тому, что употребление имен feeling, happiness, pride, hope и joy выходит за пределы идентификации только чувственной сферы, поэтому можно говорить о процессе категоризации этих имен по образу и подобию вместилища. Наблюдение за языковым материалом показало, что в большинстве своем чувства могут быть глубокими, что подтверждает $37 \%$ словоупотреблений от общего числа. В $10 \%$ они могут быть пустыми, в 9\% в них может что-то существовать/обитать, в 7\% - что-то находиться, в 5\% они могут быть заполненными, как правило, какими-то абстракциями. В остальных случаях, хоть словоупотребления и были зафиксированы, но количество их недостаточно велико, а порой вообще встречаются единичные словоупотребления, что свидетельствует об их окказиональности.

Следовательно, рассматривая существительные-чувства сквозь призму вместилища, можно обнаружить, что по аналогии с контейнером в них содержится информация уточняющего характера либо подчеркивается ее отсутствие, из них можно что-то достать, что-то получить, в них можно чтото вложить и хранить и т. д.

\section{Примечания}

1 См.: Рахилина E. Когнитивный анализ предметных имен : семантика и сочетаемость. М., 2008. С. 31.

2 Там же. С. 37.

3 Там же. C. 91.

4 Talmy L. How Language Structures Space // Spatial Orientation. Theory, Research, and Application / ed. by H. L. Pick, L. P. Acredolo. N. Y. ; L., 1983. P. 131.

5 См.: Senft $G$. What do we really know about nominal classification systems? // Systems of nominal classification / ed. by G. Senft. Cambridge, 2000. P. 13.

6 См.: Борискина О., Кретов А. Теория языковой категоризации : национальное языковое сознание сквозь призму криптокласса. Воронеж, 2003. С. 15.

7 См.: Noun Classes and Categorization : Proceedings of a Symposium on Categorization and Noun Classification, Eugene, Oregon, October 1983 / ed. by C. G. Craig. Amsterdam ; Philadelphia, 1986.

8 См.: Denny J. What are Noun Classifiers Good For? // Papers from the $12^{\text {th }}$ Regional Meeting of the Chicago Linguistic Society. Chicago, 1976. P. 122-132.

9 Allan K. Classifiers // Language. 1977. Vol. 53, № 2. P. 308.

10 Борискина О., Донина О. Английский криптокласс «RES LONGA», или И все-таки они колются // Проблемы лексико-семантической типологии : сб. науч. тр. / под ред. А. А. Кретова. Воронеж, 2011. Вып. 1. C. 85 . 
11 См.: Li P., MacWhinney B. Cryptotype, overgeneralization and competition : A connectionist model of the learning of English reversive prefixes // Connection Science. 1996. Vol. 8, № 1. P. 23.

12 См.: Собрание корпусов М. Дэвиса. URL: http://corpus. byu.edu (дата обращения: 12.02.2018).

13 См.: Davies M. Corpus of News on the Web (NOW) : 3+ billion words from 20 countries, updated every day. Provo, 2013. URL: http://corpus.byu.edu (дата обращения 15.01.2018).
14 См.: Борискина О. Криптоклассный анализ лексики : этапы и перспективы // Вестн. ТГУ. Сер. Гуманитарные науки. 2008. Вып. 6 (62). С. 45-50 ; Ееже. Криптоклассы английского языка. Воронеж, 2011 ; Ее же. Корпусное исследование криптоклассов английского языка // Компьютерная лингвистика и интеллектуальные технологии : по материалам ежегодной Междунар. конф. «Диалог» (Бекасово, 25-29 мая 2011 г.). Вып. 10 (17). М., 2011. C. 135-145.

\section{Образец для цитирования:}

Задобривская О. Ф. Чувства сквозь призму вместилища // Изв. Сарат. ун-та. Нов. сер. Сер. Филология. Журналистика. 2018. Т. 18, вып. 4. C. 408-413. DOI: https://doi.org/10.18500/1817-7115-2018-18-4-408-413

Cite this article as:

Zadobrivskaya O. F. Feelings Through the Lens of the Container. Izv. Saratov Univ. (N. S.), Ser. Philology. Journalism, 2018, vol. 18, iss. 4, pp. 408-413 (in Russian). DOI: https://doi.org/10.18500/1817-7115-2018-18-4-408-413 